\title{
CURRENT NOISE OF RESIN TYPE AND CERMET TYPE THICK FILM RESISTORS
}

\author{
SHEN-LI FU, TOYOTARO SHIRAMATSU and TIEN-SHOU WU \\ Department of Electrical Engineering, National Cheng Kung University Tainan, Taiwan, Republic of C'hina
}

(Received June 1, 1979)

\begin{abstract}
The current noise indices (C.N.I.) depend linearly on the logarithmic values of sheet resistivity $\left(\log \rho_{S}\right)$, in both carbon black/resin and thallium oxide/glass resistors, and can be expressed as C.N.I. $=A+B \log \rho_{s}$. The geometrical dependency on C.N.I. in both types of resistor can be expressed as C.N.I. $=A^{\prime}-B^{\prime} \log (L, W, T)$, where $A, B, A^{\prime}$ and $B^{\prime}$ are constants. The dependency of noise e.m.f. $\left(v_{n}\right)$ on the applied dc voltage (V), i.e., the values of $\alpha$ in $\overline{v_{n}^{2}} \propto V^{\alpha}$, can be obtained from the slope of C.N.I. versus $\log (L)$ lines, associated with a model based on the noise genera tor approximation.
\end{abstract}

\section{INTRODUCTION}

Current noise is a form of excess noise observed above the thermal and shot noise level, and is generated when direct current is passed through semiconductors. ${ }^{1}$ The same phenomena have also been observed in carbon film resistors ${ }^{2}$ and cermet type thick film resistors ${ }^{3}$ when direct current is passed through them.

Studies of current noise in semiconductors ${ }^{4-7}$ and in thick film resistors ${ }^{8}$ have been carried out. The explanations deduced from these studies are scat tered and restricted to some specified material only. The effect of resistor geometry on the C.N.I. of cermet type thick film resistors have also been studied. ${ }^{9,10}$ The C.N.I. which are usually given in units of decibels $(\mathrm{dB})$, are expressed as ${ }^{10}$

$$
\text { C.N.I. }=20 \log \frac{v_{n}}{V}(\mathrm{~dB})
$$

In this study, the relationship between C.N.I. and $\log \rho_{s}$ of both thallium oxide/glass cermet type thick film resistors and carbon black/resin thick film resistors are studied. The geometrical effects on the C.N.I. of both types of resistor have also been studied. In general, a simple model based on the contact noise approximation is adopted to explain the experimental results of both types of thick film resistor.

\section{EXPERIMENTAL PROCEDURES}

A thick film screen printing method is used to prepare the samples. Sample preparations can be divided into two main categories: resin type and cermet type.

\subsection{Resin Type Thick Film Resistors}

Conductor terminations are printed on the polyimide glass fiber laminate substrates first, then resistor films can be printed on to the terminations. The conductor is made of $\mathrm{Ag}-\mathrm{Cu}$ blend powder and resins. The resistor is prepared from carbon black powder and resins. The resins used in this study are epoxy resin and polyimide resin. Three different kinds of carbon black are used in preparing the

TABLE I

Physical properties of three different carbon blacks

\begin{tabular}{lccc}
\hline Properties & MA-600 & MA-100 & $\# 45^{a}$ \\
\hline Oil Absorption Coefficient & & & \\
(c.c./100 g) & 150 & 112 & 55 \\
Average Particle Size $(\mathrm{m} \mu)$ & 18 & 22 & 24 \\
Specific Surface Area $\left(\mathrm{m}^{2} / \mathrm{g}\right)$ & 168 & 119 & 125 \\
Volatile Matter $(\%)$ & 1.0 & 3.0 & 1.1 \\
\hline
\end{tabular}

\footnotetext{
${ }^{a}$ Trade names
} 
resistors. The screen printed films are dried at $80^{\circ} \mathrm{C}$ for two hours and then cured in a thermostat furnace. The curing conditions are different when different resins are used. The curing temperature is limited by the substrate material. One of the reasons why polyimide fiber laminates are used as substrate materials is that they can be cured at higher temperatures. The trade names and physical properties of the three carbon blacks are listed in Table I.

\subsection{Cermet Type Thick Film Resistors}

The conductors are made of $\mathrm{Ag}$ powder and glass frits. The glass frits used in this study are lead borosilicate glass $\left(\mathrm{PbO}: \mathrm{B}_{2} \mathrm{O}_{3}: \mathrm{SiO}_{2}\right)$ modified by $10 \%$ (wt.) $\mathrm{ZnO}$ or $\mathrm{ZrO}_{2}$. The glass frit used in conductor termination and that used in overlapped resistor is the same. The printed films are first dried at $100^{\circ} \mathrm{C}$ for 10 minutes to 20 minutes, and then co-fired at $575^{\circ} \mathrm{C}$ for 12.5 minutes in a conveyor furnace. The peak temperature is $575^{\circ} \mathrm{C}$ and 12.5 minutes is the total in-furnace time. The substrates used in preparing samples are $96 \%$ alumina ceramic substrates. The solvent used is butyl cellosolve. Ethyl cellulose is used as viscosity controller, and lecithin as a surfacant.

\subsection{Measurements}

Sheet resistivity (in ohm/sq.) can be measured by a digital multimeter. The thickness is controlled by the Weltek AT-44 Precision Screen-Printer, and checked by an interference thickness gauge for thick film use. Current Noise Indices are obtained by a Quan-Tech 315B noise meter.

\section{RELATIONSHIP BETWEEN SHEET RESISTIVITY AND C.N.I.}

\subsection{Cermet Type: Thallium Oxide/Glass Resistors}

Figure 1 shows the relationship between the C.N.I. and the sheet resistivity $\left(\log \rho_{s}\right)$. They are linearly dependent. The same results have been observed in another kind of cermet type thick film resistor. ${ }^{11}$ The linear dependency can be expressed as

$$
\text { C.N.I. }=A+B \log \rho_{s}
$$

where $A$ and $B$ are constants. However, the value of $B$ deduced by Bristow, ${ }^{10}$ based on an assumption that $v_{n}^{\overline{2}} \propto V^{2}$, will be $B=10$. The value obtained

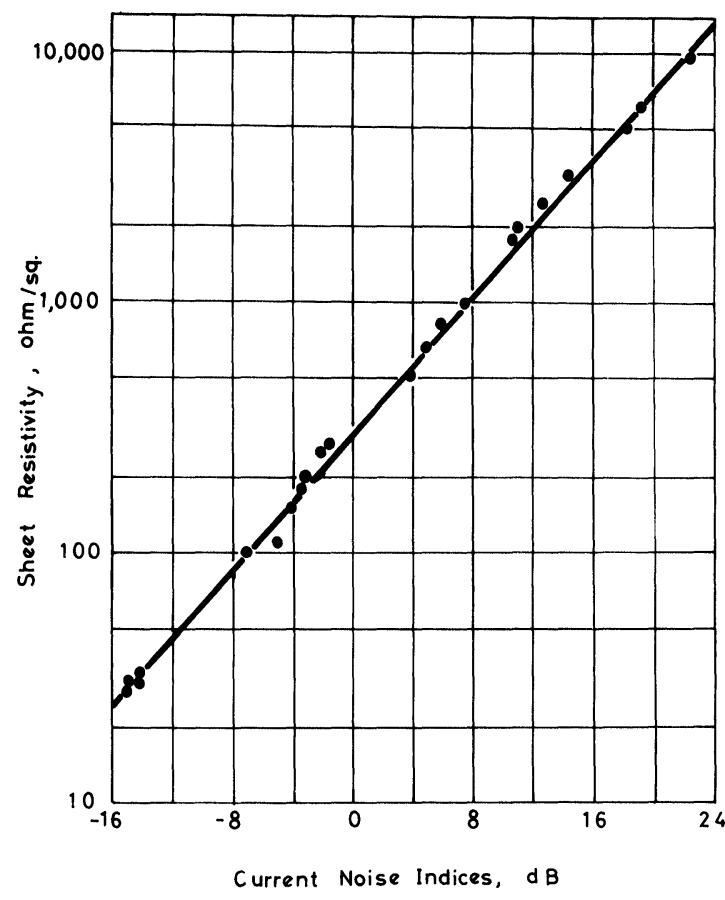

FIGURE 1 C.N.I. vs $\log \rho_{s}$ of thallium oxide/glass resistors.

from the slope of the line shown in Figure 1 will be $B \simeq 14$. This might be taken as evidence that the dependency of noise e.m.f., $v$, on the applied dc voltage, $V$, of thallium oxide/glass resistor is $\bar{v}_{n}^{2} \propto V^{\alpha}$, where $\alpha \neq 2$.

\subsection{Resin Type: Carbon Black/Resin Resistors}

The relationships between C.N.I. and $\log \rho_{s}$ of carbon black/resin resistors are shown in Figure 2 (epoxy resin) and Figure 3 (polyimide resin). In both figures three lines, corresponding to three different kinds of carbon black, are shown. However, there is a turning point observed for each line on both figures. Above the turning points, the C.N.I, increases with an increase in $\log \rho_{s}$. The tendency is the same as that shown in Figure 1. The values of $B$ obtained from the slopes of the lines above turning points are $11 \leqslant B \leqslant 27$. This result also implies that the dependency of $v_{n}$ on $V$ is not exactly $\overline{v_{n}^{2}} \propto V^{2}$.

The increase in C.N.I. associated with an increase in $\log \rho_{s}$ can be understood by considering contact noise. It is known that an increase in the contents of conducting material (thallium oxide and carbon black), will increase the number of conducting 


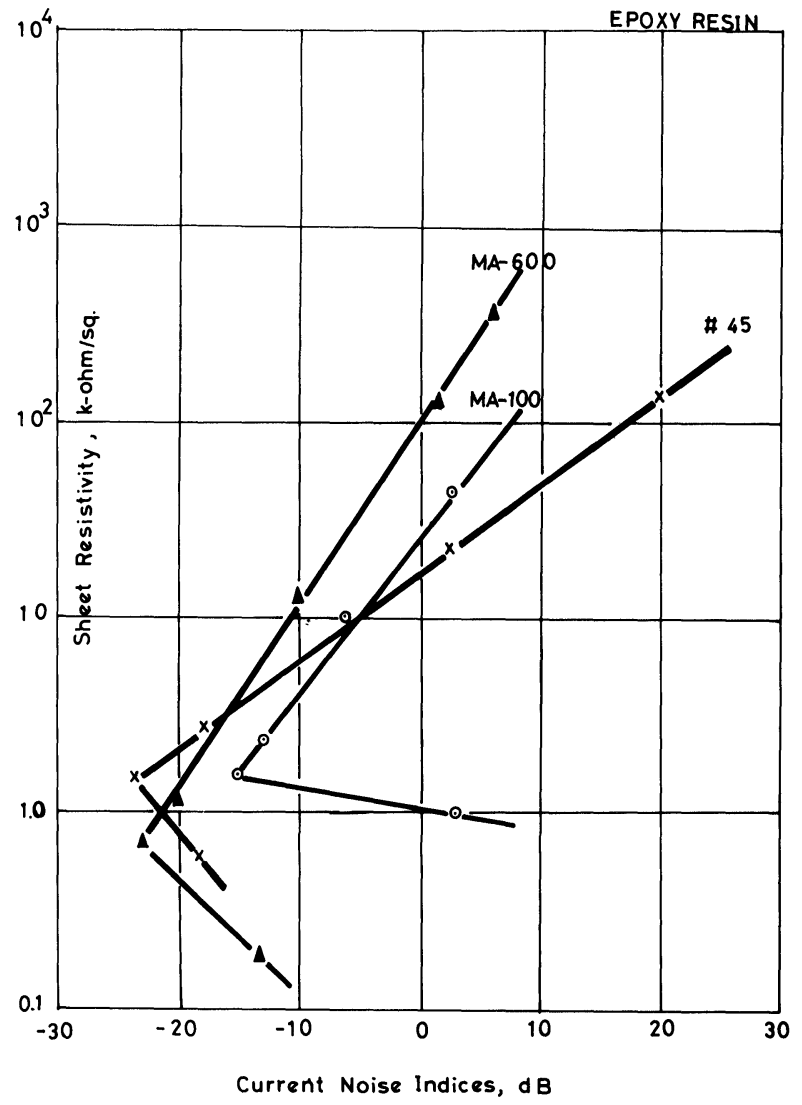

FIGURE 2 C.N.I. vs $\log \rho_{s}$ of carbon black/epoxy resin resistors.

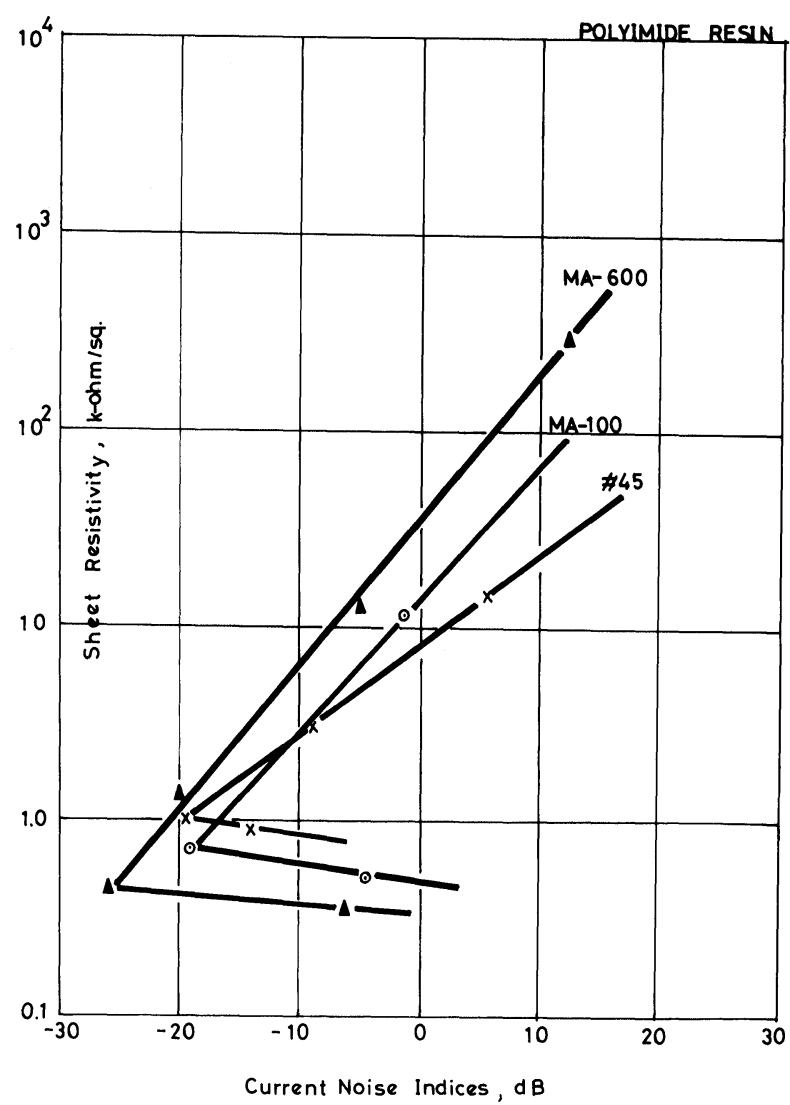

FIGURE 3 C.N.I. vs $\log \rho_{s}$ of carbon black/polyimide resin resistors.

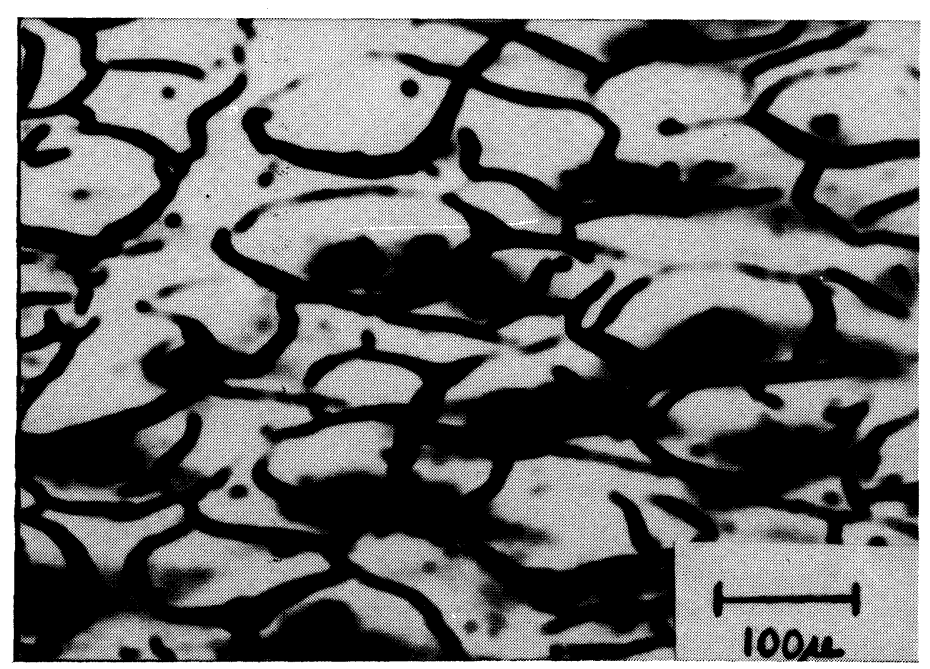

FIGURE 4 The cracks observed on the MA-600 carbon black/epoxy resin resistor. 
particles that are connected in series along the direction of applied dc voltage, and cause the C.N.I. to decrease. ${ }^{1}$

Below the turning points, however, an increase in C.N.I. will be observed for a decrease in $\log \rho_{s}$. Such phenomena are attributed to the poor printability of the resistors when the contents of carbon black exceed a certain level. Figure 4 shows the cracks observed on a MA-600 carbon black/epoxy resin resistor (MA-600:Epoxy $=40: 60$, wt.). The cracks observed may be the cause of the increase in C.N.I. when the amount of carbon black exceeds a certain level.

\section{EFFECTS OF RESISTOR GEOMETRY ON CURRENT NOISE}

\subsection{Cermet Type: Thallium Oxide/Glass Resistors}

The effects of resistor geometries on the C.N.I. of thallium oxide/glass thick film resistors are shown in Figure 5. In Figure 5(a) and Figure 5(b), the effects (a)

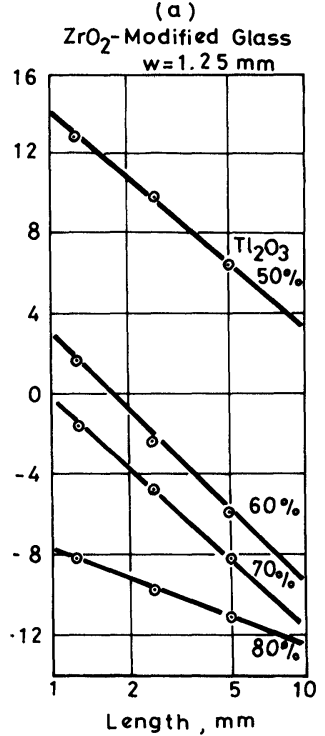

(b)

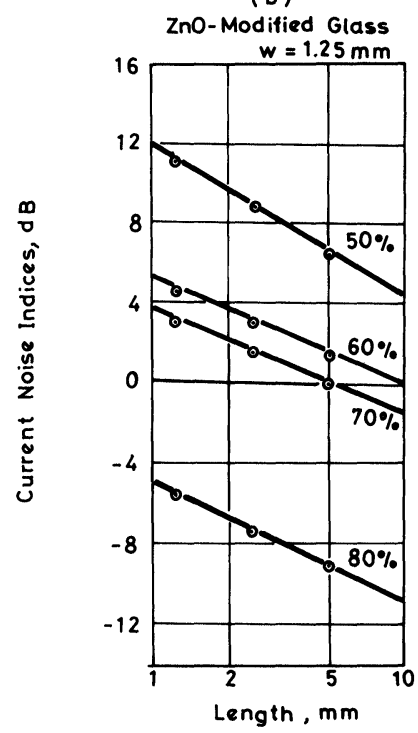

general equation as

$$
\text { C.N.I. }=A^{\prime}-B^{\prime} \log (L, W, T)
$$

where $A^{\prime}, B^{\prime}$ are constants and $L, W, T$ are the length, width and thickness of the resistor. Effects of resistor area and volume on C.N.I. have not been included in this report.

\subsection{Resin Type: Carbon Black/Polyimide Resin Resistors}

The geometrical effects of carbon black/polyimide resin resistors are shown in Figure 6. Figure 6(a) shows the effect of resistor length on the C.N.I., while Figure 6(b) shows the effect of the aspect ratio $(L / W)$ and the volume of the resistor on C.N.I. Note that the C.N.I. in Figure 6 are not always higher for resistors with lower contents of carbon black. The results coincide with the results shown in Figure 3. (a)

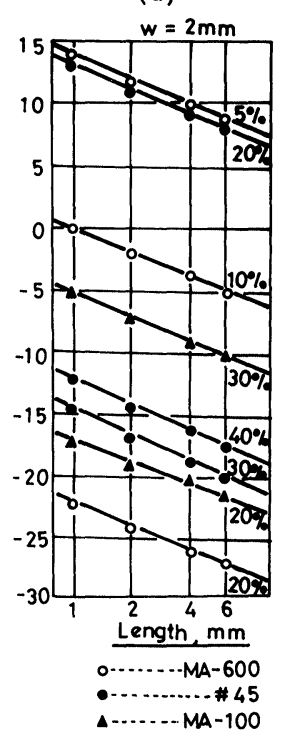

(b)

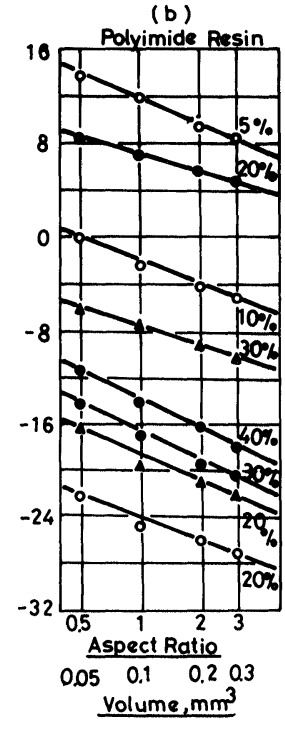

FIGURE 6 (a) C.N.I. versus resistor length, (b) C.N.I. versus volume and aspect ratio of carbon black/polyimide resin resistors.

\section{DEPENDENCY OF NOISE E.M.F. ON APPLIED DC VOLTAGE}

In order to find out the dependency of noise e.m.f. on the applied dc voltage, i.e., to find the value $\alpha$ in $\overline{v_{n}^{2}} \propto V^{\alpha}$, an experimental approach using Bristow's 
model is used as follows:

The C.N.I. deduced from Bristow's noise generator model, can be formulated as ${ }^{10}$

$$
\text { C.N.I }=20 \log \left[\frac{K}{g^{\alpha / 2}} \cdot \frac{L^{(1 / 2-\alpha / 2)}}{W^{1 / 2}} \cdot V^{(\alpha / 2-1)}\right]
$$

The width is kept constant in both types of resistor. In measuring the C.N.I. the applied dc voltage is adjusted automatically, according to the resistance value, by a reference power of $100 \mathrm{~mW}$. The relationship between C.N.I. and $\log (L)$ can be obtained as

$$
\text { C.N.I. }=C^{\prime}-5 \alpha \cdot \log (L)
$$

where $C^{\prime}$ is a composite constant. The values obtained from the slope of C.N.I. versus $\log (L)$ lines are: $1.5 \leqslant \alpha \leqslant 2.5$ for thallium oxide $/ \mathrm{ZrO}_{2}$ modified glass resistors and $1.1 \leqslant \alpha \leqslant 1.5$ for thallium oxide/ZnO-modified glass resistors. For carbon black/polyimide resin resistors, the value obtained from Figure 6 (a) is $\alpha \simeq 1.4$.

\section{CONCLUSION}

The properties of current noise in both resin type (carbon black/resin) and cermet (thallium oxide/ glass) thick film resistors have been studied. Common points have been obtained and explained by the same mechanism.

The C.N.I. vary linearly with $\log \rho_{s}$ in both carbon black/resin and thallium oxide/glass resistors, and can be expressed as C.N.I. $=A+B \log \rho_{s}$ where $A$ and $B$ are constants.

The geometrical effects on C.N.I. can be expressed as C.N.I. $=A^{\prime}-B^{\prime} \log (L, W, T)$ in both types of thick film resistors. The dependency of noise e.m.f. on applied dc voltage can be obtained from C.N.I. vs $\log (L)$ lines with the aid of a model based on noise generator approximation.

\section{ACKNOWLEDGEMENT}

The authors wish to thank the National Council of Science of R.O.C. for financial support on this study.

\section{REFERENCES}

1. Van Der Ziel, Noise, (Prentice-Hall, New York 1950).

2. T. R. Williams IRE Trans. Components and Parts, CP-6 (1959) 58.

3. J. A. Ringo, E. H. Stevens and D. A. Gilbert, IEEE Trans. Parts, Hybrids and Packag, PHP-12 (1976) 351.

4. D. A. Bell, Brit. J. Appl. Phys. 6 (1955) 284.

5. O. Jantsch, Solid-State Electron., 11 (1968) 267.

6. F. N. Hooge, Phys. Lett. 29A (1960) 139.

7. F. N. Hooge, Physica, 60 (1972) 130.

8. C. A. Harper, Handbook of thick film hybrid microelectronics, (McGraw-Hill, 1974) chapter 6.

9. C. Y. Kuo, Proc. ISHM, (1968) p. 153.

10. C. W. H. Bristow, W. L. Clough and P. L. Kirby, Proc. ISHM, (1971) p. 7-6-1.

11. D. L. Herbst, Proc. ISHM, (1968) p. 173. 

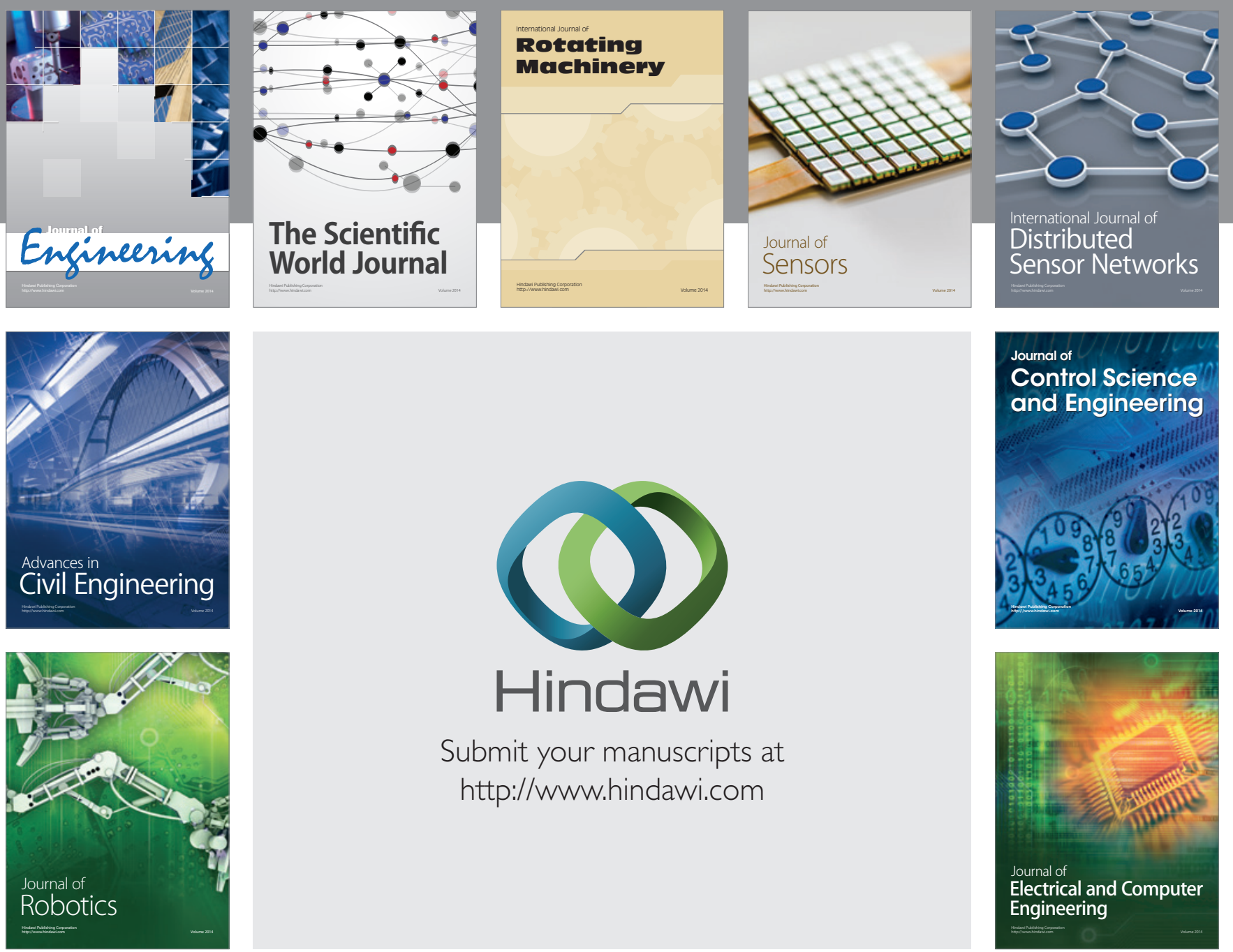

Submit your manuscripts at

http://www.hindawi.com
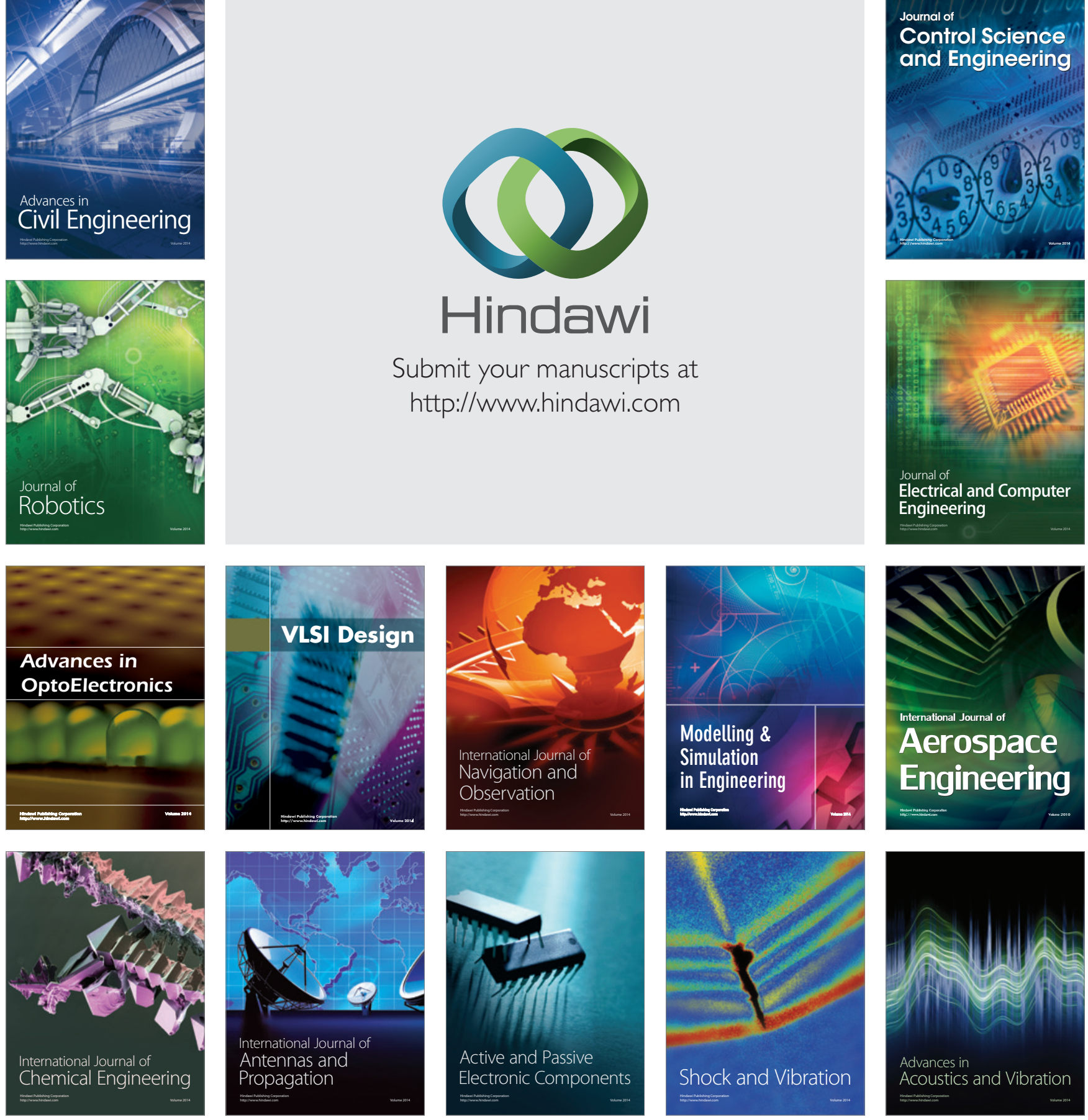